\title{
All-trans retinoic acid can antagonize osteoblastogenesis induced by different BMPs irrespective of their dimerization types and dose-efficiencies
}

This article was published in the following Dove Press journal:

Drug Design, Development and Therapy

Yi Liu, ${ }^{1, *}$ Xiaoqing Ma, ${ }^{2, *}$ Jing Guo,' Zhen Lin, ${ }^{3}$ Miao Zhou,' Wenjuan $\mathrm{Bi}^{4}{ }^{4}$ Jinsong $\mathrm{Liu},{ }^{5}$ Jingxiao Wang, ${ }^{6}$ Haiping Lu, ${ }^{7, *}$ Gang Wu ${ }^{8, *}$

'Key Laboratory of Oral Medicine, Guangzhou Institute of Oral Disease, Stomatology Hospital of Guangzhou Medical University, Guangzhou Medical University, Guangzhou 510140, China; ${ }^{2}$ Shanghai Xuhui District Dental Center, Shanghai 200032, China; ${ }^{3}$ Department of Orthopedics, The First Affiliated Hospital of Jinan University, Guangzhou 510630 , China; ${ }^{4}$ College of Stomatology, North China University of Science and Technology, Tangshan 063000, China; ${ }^{5}$ School and Hospital of Stomatology, Wenzhou Medical University, Wenzhou 325000, China; ${ }^{6}$ The First Affiliated Hospital, Wenzhou Medical University, Wenzhou 325000, China; ${ }^{7}$ School of Stomatology, Zhejiang Chinese Medical University, Hangzhou 310053, China;

${ }^{8}$ Department of Oral Implantology and Prosthetic Dentistry, Academic Centre for Dentistry Amsterdam (ACTA), University of Amsterdam and Vrije Universiteit Amsterdam, 108ILA Amsterdam, the Netherlands

*These authors contributed equally to this work

Correspondence: Haiping Lu School of Stomatology, Zhejiang Chinese Medical University, Binwen Road 548, Hangzhou, 310053 , China

Tel +86 57l 86633080

Email haipinglushu@hotmail.com

Gang Wu

Department of Oral Implantology and Prosthetic Dentistry, Academic Centre for Dentistry Amsterdam (ACTA), Universiteit van Amsterdam and Vrije Universiteit Amsterdam, Gustav Mahlerlaan 3004, I08ILA Amsterdam, the Netherlands

Tel +3I 205980866

Email g.wu@acta.nl
Introduction: Alcoholism can lead to low mineral density, compromised regenerative bone capacity and delayed osteointegration of dental implants. This may be partially attributed to the inhibitive effect of all-trans retinoic acid (ATRA), a metabolite of alcohol, on osteoblastogenesis. Our previous studies demonstrated that heterodimeric bone morphogenetic protein 2/7 (BMP2/7) was a more potent BMP than homodimeric BMP2 or BMP7, and could antagonize the inhibitive effect of ATRA to rescue osteoblastogenesis.

Materials and methods: In this study, we compared the effectiveness of BMP2/7, BMP2 and BMP7 in restoring osteoblastogenesis of murine preosteoblasts upon inhibition with $1 \mu \mathrm{M}$ ATRA, and we further analyzed the potential mechanisms. We measured the following parameters: cell viability, ALP, OCN, mineralization, the expression of osteogenic differentiation marker genes (Collagen I, ALP and $\mathrm{OCN}$ ) and the expression of BMP signaling key genes (Dlx5, Runx2, Osterix and Smad1).

Results: BMP2/7 treatment alone induced significantly higher osteoblastogenesis compared to BMP2 and BMP7. When cells were treated by ATRA, BMP2/7 was superior only in rescuing cell viability and ALP activity, compared to BMP2 or BMP7. However, BMP2/7 was not superior to BMP2 or BMP7 in restoring OCN expression and extracellular mineralized nodules, or in rescuing expression of two key osteogenic genes, Dlx5 and Runx2. Irrespective of their dimeric types or potency, the selected BMPs could antagonize the inhibitory effect of ATRA on osteoblastogenesis.

Conclusion: The presence of ATRA, BMP2/7 still induced significantly higher cell viability and early differentiation than the homodimers. However, ATRA significantly attenuated the advantages of BMP2/7 in inducing late and final osteoblastogenic differentiation over the homodimers.

Keywords: heterodimeric, homodimeric, bone morphogenetic protein, osteoblastogenesis, all-trans retinoic acid

\section{Introduction}

Bone formation and remodeling are lifelong biological events that are of paramount importance to maintain the volume, density and function of bone tissue. During bone formation and remodeling, osteoprogenitors undergo osteoblastogenesis, which involves a series of sequential cellular and molecular events, including proliferation, differentiation and extracellular matrix mineralization. ${ }^{1}$ Osteoblastogenesis is carefully regulated by various factors in the bone microenvironment and is highly sensitive to adverse systemic conditions, such as alcoholism.

Alcoholism is a highly prevalent addiction. In 2015, the estimated prevalence among the adult population was $18.4 \%$ for heavy episodic drinking. ${ }^{2}$ Alcohol abuse is 
associated with more harmful detrimental effects than nicotine use. ${ }^{3}$ Chronic alcohol abuse leads to low bone mass, ${ }^{4-7}$ bone fragility and spontaneous fractures. ${ }^{4,8-10}$ Animal studies showed that alcohol consumption significantly reduces new bone formation ${ }^{11}$ and delays osteointegration of implants, ${ }^{12}$ possibly by reducing the number and activity of osteoblasts. ${ }^{13}$ Alcoholism can also result in compromised osteoinduction, leading to impaired healing of bone defects. ${ }^{13}$ Furthermore, prenatal alcohol exposure also significantly affects fetal bone development. ${ }^{14}$ However, the mechanisms accounting for these phenomena remain unclarified. A potential mechanism could be that chronic alcohol abuse significantly increases the concentration of all-trans retinoic acid (ATRA), ${ }^{15}$ a metabolite of alcohol, resulting in compromised osteoblastogenesis. ${ }^{16}$ ATRA can control bone differentiation pathways during early organogenesis. ${ }^{17}$ ATRA regulates the gene expression via its receptors. There are two families of retinoic acid receptors, RARs and RXRs, each of which has three isotypes $(\alpha, \beta$ and $\gamma)$.

To promote bone regeneration for repairing bone defects in patients with alcoholism, one strategy is to adopt potent osteoinductive growth factors, such as bone morphogenetic proteins (BMPs). BMPs comprise a group of disulfide bondlinked dimeric proteins and belong to the superfamily of transforming growth factor- $\beta$. BMPs, particularly BMP-2 and BMP-7 in absorbable collagen sponge, have been approved by the FDA for promoting bone regeneration in clinical settings. ${ }^{18,19}$ BMP ligands bind to transmembrane BMP receptors, resulting in enhanced levels of phosphorylated Smad1/5 (p-Smad1/5). P-mad1/5 forms a complex with Smad4 and translocates into the nucleus to induce the expression of Dlx $5 .{ }^{20}$ Dlx 5 upregulates two critical osteogenic genes: Runx $2^{21}$ and Osterix. ${ }^{22}$ BMPs facilitate osteoblastogenic cellular events, such as collagen secretion, differentiation (indicated by the expression of ALP and $\mathrm{OCN}$ ) and mineralization of extracellular matrix. ${ }^{23,24}$ BMP2 and BMP7, in combination with carriers, have been approved for clinical application to accelerate and enhance bone regeneration and implant osteointegration. ${ }^{18}$ However, the clinical doses of homodimeric BMPs are extremely high (eg, up to milligrams), ${ }^{25,26}$ and not only lead to a heavy economic burden on patients, but also can induce a series of potential side effects, including overstimulated osteoclastic activity and ectopic bone formation. ${ }^{27,28}$

One potential solution is to use heterodimeric BMP to stimulate osteoblastogenesis. Heterodimeric BMP is more potent than homodimeric BMP; we previously demonstrated that heterodimeric BMP2/7 induced osteoblastogenesis at significantly lower optimal concentrations than homodimeric
BMPs. ${ }^{23}$ In an in vivo peri-implant bone defect model, we reported that low-dose BMP2/7 heterodimer facilitated more rapid and better quality bone regeneration than homodimeric BMPs. ${ }^{29}$ Thereafter, we explored the utility of BMPs to promote osteoblastogenesis in alcoholic patients, and we demonstrated that heterodimeric BMP2/7 antagonized the inhibitory effect of ATRA and could rescue osteoblastogenesis. ${ }^{30,31}$

However, it remains unclear whether the more potent heterodimeric BMP2/7 is superior to homodimeric BMP2 or BMP7 in antagonizing ATRA and promoting osteoblastogenesis. In this study, we aimed to compare the effects of BMP2/7 heterodimer to those of BMP2 and BMP7 homodimers in promoting osteoblastogenesis in the presence of $1 \mu \mathrm{M}$ ATRA. We used a murine calvaria-derived cell line (MC3T3-E1), one of the most convenient and physiologically relevant model systems to study bone regeneration. ${ }^{32}$ MC3T3-E1 cell line is also one of most frequently adopted cell model to investigate the effect of ATRA on osteoblastogenesis. ${ }^{33}$ Our ultimate objective is to choose the more effective BMPs that have potential for facilitating bone regeneration and implanting osteointegration for patients with excessive alcohol consumption.

\section{Materials and methods Study design}

We assessed the stimulatory effect of $50 \mathrm{ng} / \mathrm{mL} \mathrm{BMP2/7}$ heterodimer, BMP2 homodimer or BMP7 homodimer on osteoblastogenesis of preosteoblasts in the presence or absence of $1 \mu \mathrm{M}$ ATRA. The concentration of BMP was based on our previous studies. ${ }^{23}$ In addition, $1 \mu \mathrm{M}$ ATRA was regularly used to study the in vitro effects of ATRA on osteogenic differentiation. . $^{34,35}$

We evaluated osteoblastogenesis by gauging cell viability, ALP activity (as a marker of early stage differentiation), OCN (as a marker of late-stage differentiation) and cellular matrix mineralized nodules (as the marker of final differentiation), as well as expression of key genes involved in osteoblastogenesis-related signaling pathways, including Smad1, Dlx5, Runx2 and Osterix.

\section{Cell culture}

MC3T3-E1 preosteoblast cells (subclone 4; ATCC CRL2594) were cultured in $\alpha$-minimum essential medium $(\alpha-\mathrm{MEM})$ containing 10\% FBS (Gibco ${ }^{\circledR}$, Invitrogen, Grand Island, NY, USA). Culture medium was changed every 3 days. Exponentially growing cells $(\mathrm{f}=0.662$ [cell cycle per day]) were plated in 24-well plates at a final concentration of $5 \times 10^{4}$ cells/well for the cell proliferation assay, at $2 \times 10^{5}$ cells/well in six-well plates for the ALP activity assay, 
OCN detection and PCR analysis, or at $3 \times 10^{4}$ cells/well in 48-well plates for alizarin red staining. For all analyses except for alizarin red staining, after 24 hours incubation, cells were cultured in low-serum medium ( $\alpha$-MEM containing $1 \%$ FBS) for an additional 24 hours. Cells were then treated with different combinations of heterodimeric BMP2/7 (R\&D Systems, Inc., Minneapolis, MN, USA), BMP-2 homodimer (R\&D Systems, Inc.), BMP-7 homodimer (R\&D Systems, Inc.) and/or ATRA (Sigma-Aldrich, St Louis, MO, USA). Experiments were performed on six biological replicate samples per group per time point, and each experiment was performed for at least two independent times to confirm the results.

\section{Cell viability assay}

Cell viability and proliferation of each group were determined using the AlamarBlue ${ }^{\circledR}$ cell viability reagent (Invitrogen Corporation, Carlsbad, CA, USA) after treatment with BMPs for 1 day, 4 days and 7 days. Fluorescence intensity was measured using a fluorescent spectrometer (SpectraMax M5 Molecular Devices, Sunnyvale, CA, USA) at EX $540 \mathrm{~nm} /$ EM 590 nm.

\section{ALP activity assay}

Early osteogenic differentiation of preosteoblasts was assessed by assessing ALP activity assay. ALP activity and total protein content were measured after treatment with BMPs for 4 days and 7 days. The ALP activity in the cell lysate (Sigma-Aldrich) was determined using LabAssay ${ }^{\mathrm{TM}}$ ALP colorimetric assay kit (Wako Pure Chemicals, Osaka, Japan). The total protein content was measured at $570 \mathrm{~nm}$ using a commercial BCA Protein Assay kit (Beyotime, Shanghai, China). Values were expressed as nmol p-NP/ $\mu \mathrm{g}$ total protein/hour to indicate the ALP activity.

\section{OCN expression assay}

OCN secreted into cell culture medium was determined to assess the terminal differentiation of preosteoblasts. Cell supernatants were collected and centrifuged $(10,000 \mathrm{rpm}$, $4^{\circ} \mathrm{C}, 5$ minutes) on day 4 and day 7 before analysis. The OCN concentration was determined by ELISA using a mouse OCN EIA kit (Biomedical Technologies, Stoughton, MA, USA). ${ }^{23,36}$

\section{Alizarin red staining}

Alizarin red staining was used to assess the final mineralized nodules in each group. We compared the area of mineralized nodules in samples stimulated with BMP2/7, BMP2, BMP7 and/or ATRA. MC3T3-E1 cells were treated in the same way as described previously ${ }^{37}$ and then treated with mineralizing medium (10\% FBS, $50 \mu \mathrm{g} / \mathrm{mL}$ L-ascorbic acid and $10 \mathrm{mM} \beta$-glycerophosphate; Sigma-Aldrich) containing BMP2/7 and/or ATRA. The medium was replaced every 3 days. On day 21 and day 28, mineralized nodules were determined by alizarin red staining (Sigma-Aldrich), as previously described. ${ }^{37}$ Culture plates were photographed by NIS-Elements F2.20 (Nikon Eclipse 80i, Tokyo, Japan), and the calcified areas were then quantified using Image-Pro Plus 6.0 software.

\section{Isolation of total RNA and real-time fluorescence quantitative PCR (RT-qPCR) analysis}

Total RNA was extracted from the cells treated with BMPs and/or ATRA using an RNeasy Mini Kit and purified with RNase-Free DNase Set reagent (Qiagen, Hilden, Germany), following the manufacturer's instructions, on day 4 and day 7. Total RNA was reverse transcribed to cDNA using a PrimeScript ${ }^{\circledR}$ RT Master Mix kit (Perfect Real Time, Takara, Tokyo, Japan). RT-qPCR was performed using a PrimeScript ${ }^{\circledR}$ RT reagent kit (Perfect Real Time, Takara), according to the manufacturer's instruction. Specific primers used for detecting mRNA transcripts of the $A L P, O C N$, Collagen I, Runx2, Dlx5, Osterix, Smad1 and $\beta$-actin genes are shown in Table 1. Gene expression was normalized to the $\beta$-actin transcript levels. The $n$-fold upregulation for each gene of interest was calculated over the internal control gene ( $\beta$-actin gene) according to the $\Delta \Delta \mathrm{Ct}$ method using the formula: $2-[(\mathrm{CT}$ gene of interest-CTinternal control) sample-(CT gene of interest-CT internal control) control]. ${ }^{38}$

\section{Statistical analysis}

All data are presented as mean $\pm \mathrm{SD}$. Comparisons between groups were made by one-way ANOVA. Post hoc comparisons were made using Bonferroni corrections. The level of significance was set at $P<0.05$. SPSS software (version 20) for a Windows computer system was used for statistical analysis.

\section{Results Cell viability}

The cell viability in each group was determined by the AlamarBlue ${ }^{\circledR}$ Cell Viability Assay. On day 1, neither ATRA nor BMPs showed a significant effect on the viability of preosteoblasts (Figure 1). On day 4 and day 7, treatment with $1 \mu \mathrm{M}$ ATRA resulted in significant reduction of cell viability compared to the control (no BMP, no ATRA). 
Table I Primer sequences for real-time quantitative PCR analysis of the expression of ALP, OCN genes, Collagen I, Runx2, Dlx5, Osterix and SmadI

\begin{tabular}{|c|c|c|}
\hline Gene & Accession no & Primers ( $F=$ forward; $R=$ reverse) \\
\hline Akp2 & NM_00743I & F: 5'-TGCCTACTTGTGTGGCGTGAA-3'; \\
\hline$(\mathrm{ALP})$ & & R: 5'-TCACCCGAGTGGTAGTCACAATG-3' \\
\hline \multirow[t]{2}{*}{ OCN } & NM_00754I & F: 5'-AGCAGCTTGGCCCAGACCTA-3'; \\
\hline & & R: 5'-TAGCGCCGGAGTCTGTTCACTAC-3' \\
\hline \multirow[t]{2}{*}{ Collagen I } & NM_007742 & F: 5'-ATGCCGCGACCTCAAGATG-3'; \\
\hline & & R: 5'-TGAGGCACAGACGGCTGAGTA-3' \\
\hline \multirow[t]{2}{*}{ Runx2 } & NM_009820 & F: 5'-CACTGGCGGTGCAACAAGA-3'; \\
\hline & & R: 5'-TTTCATAACAGCGGAGGCATTTC-3' \\
\hline \multirow[t]{2}{*}{ Dlx5 } & NM_0I0056 & F: 5'-GACGCAAACACAGGTGAAA-3'; \\
\hline & & R: 5'-CGAGTTACACGCCATAGGG-3' \\
\hline \multirow[t]{2}{*}{ Osterix } & AY_803733 & F: 5'-TTTCTGCGGCAAGAGGTTCA-3'; \\
\hline & & R: 5'-TGCTCAAGTGGTCGCTTCTG-3' \\
\hline \multirow[t]{2}{*}{ Smadl } & XM_006530746 & F: 5'-GAGATGTTCAGGCAGTTGCT-3'; \\
\hline & & R: 5'-CTTCACCCACACGGTTGTT-3' \\
\hline \multirow[t]{2}{*}{$\beta$-Actin } & NM_007393 & F: 5'-AGGAGCAATGATCTTGATCTT-3'; \\
\hline & & R: 5'-TGCCAACACAGTGCTGTCT-3' \\
\hline
\end{tabular}

By contrast, treatment with BMP2/7, but not BMP2 or BMP7, resulted in significantly enhanced cell viability. Treatment with $1 \mu \mathrm{M}$ ATRA significantly compromised the effect of BMP2/7 on day 4 and day 7 , and also reduced viability in cells treated with BMP7 on day 4. On day 7, only treatment with BMP2/7, but not BMP2 or BMP7, was able to rescue reduced cell viability induced by ATRA to a level that was higher than the control.
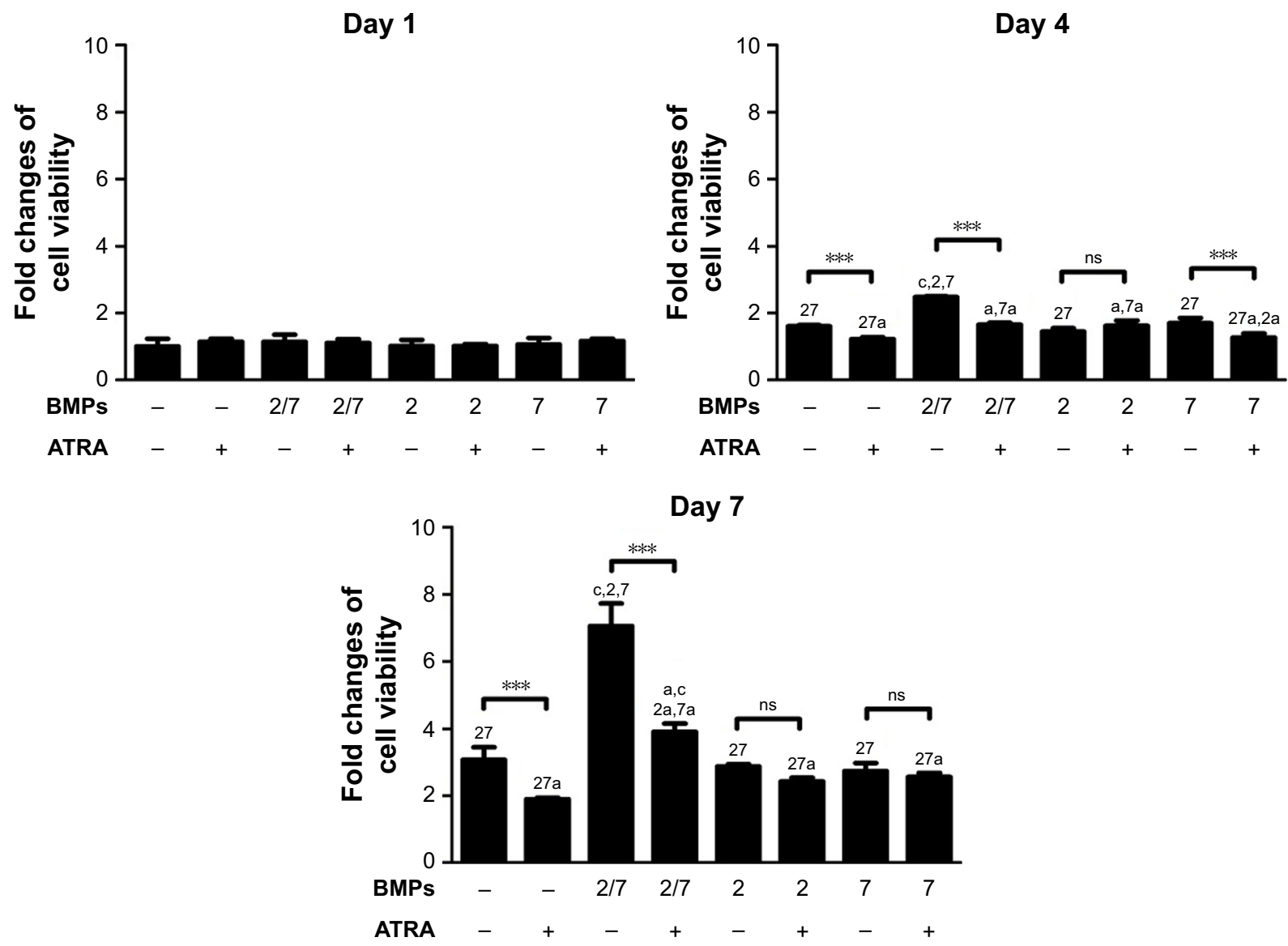

Figure I The cell numbers of murine calvarial pre-osteoblasts (MC3T3-EI cells) per well under the different treatments.

Notes: I) no ATRA, no BMPs (c); 2) I $\mu$ M ATRA, no BMPs (a); 3) no ATRA, 50 ng/mL BMP2/7 (27); 4) I $\mu$ M ATRA, 50 ng/mL BMP2/7 (27a); 5 ) no ATRA, 50 ng/mL BMP2 (2); 6) I $\mu$ M ATRA, $50 \mathrm{ng} / \mathrm{mL}$ BMP2 (2a); 7) no ATRA, $50 \mathrm{ng} / \mathrm{mL}$ BMP7 (7); 8) I $\mu$ M ATRA, $50 \mathrm{ng} / \mathrm{mL}$ BMP7 (7a) for I day, 4 days and 7 days. All data are presented as mean values together with the standard deviation (SD). ${ }^{*} p<0.05, * * p<0.01$, *** $p<0.00$ I.

Abbreviation: ns, not significant. 

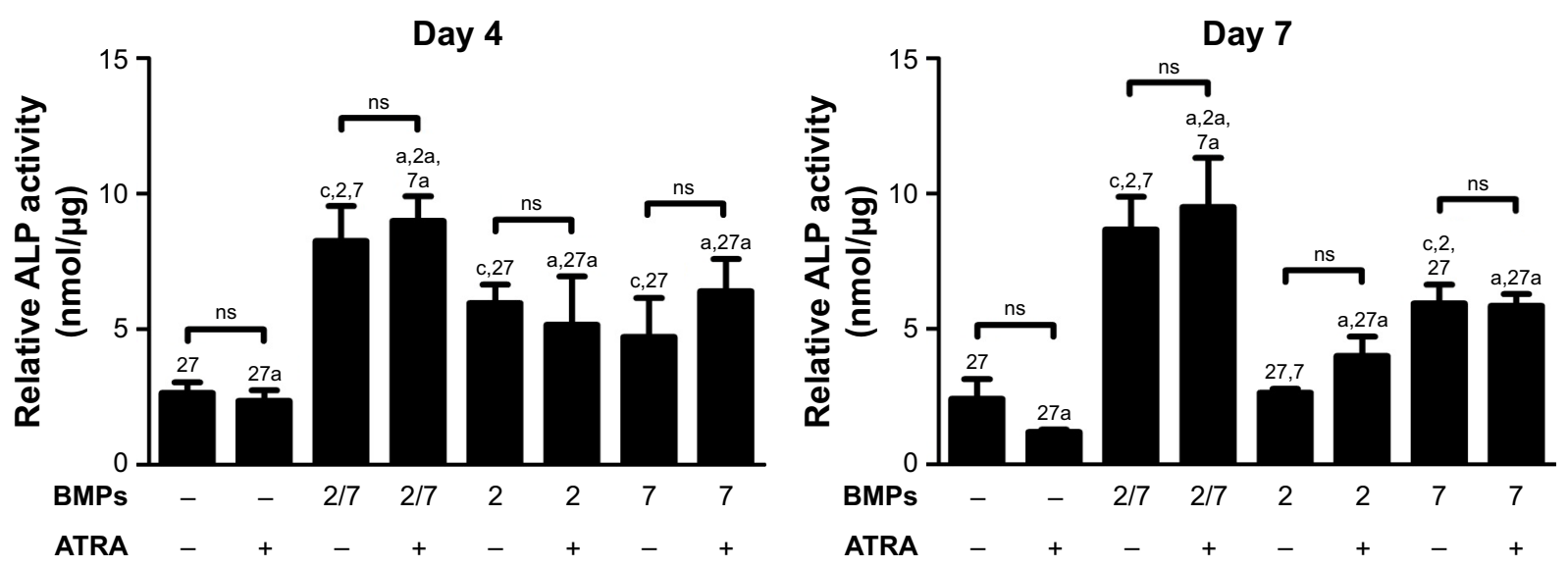

Figure 2 The activity of alkaline phosphatase (ALP) of murine calvarial pre-osteoblasts (MC3T3-EI cells) under the different treatments.

Notes: I) no ATRA, no BMPs (c); 2) I $\mu$ M ATRA, no BMPs (a); 3) no ATRA, 50 ng/mL BMP2/7 (27); 4) I $\mu$ M ATRA, 50 ng/mL BMP2/7 (27a); 5 ) no ATRA, 50 ng/mL BMP2 (2); 6) I $\mu$ M ATRA, 50 ng/mL BMP2 (2a); 7) no ATRA, $50 \mathrm{ng} / \mathrm{mL}$ BMP7 (7); 8) I $\mu$ M ATRA, 50 ng/mL BMP7 (7a) after for 4 day and 7 days. The ALP activity was normalized to total cellular protein content. All data are presented as mean values together with the standard deviation (SD). ${ }^{*} p<0.05$, ${ }^{* *} p<0.0 \mathrm{I}, * * * p<0.00 \mathrm{I}$.

Abbreviation: ns, not significant.

\section{ALP activity}

On day 4 and day 7, treatment with each BMP alone was able to induce higher ALP activities than the control (no BMP, no ATRA; Figure 2). Treatment with BMP2/7 alone induced higher ALP activities than BMP2 or BMP7. On both day 4 and day 7 , treatment with ATRA did not significantly influence ALP activity, regardless of the presence or absence of the various BMP treatments.

\section{OCN expression}

On both day 4 and day 7, treatment with BMP2/7, BMP2 or BMP7 induced higher OCN expression than control (no BMP, no ATRA; Figure 3). Treatment with BMP2/7 alone induced higher OCN expression than BMP2 or BMP7 on day 4 and day 7. By contrast, treatment with ATRA significantly decreased OCN expression both in the absence of BMPs and in the presence of BMP2/7 and BMP7. The reduction in OCN expression resulting from treatment with ATRA was restored to a similar level as the control by treatment with all the BMPs. Interestingly, on day 7, OCN expression in the BMP2/7 + ATRA treatment group was significantly lower than in the groups treated with BMP2 or BMP7 alone with the addition of ATRA.

\section{Evaluation of cellular matrix mineralized nodules} On both day 21 and day 28, treatment with BMP2/7, BMP2, or BMP7 induced a greater number of mineralized nodules than the control (no BMP, no ATRA; Figure 4). Furthermore, treatment with BMP2/7 alone significantly induced a greater number of mineralized nodules than BMP2 or BMP7 at both time points. In contrast, treatment with ATRA significantly decreased production of cell matrix mineralized nodules both in the absence and in the presence of BMPs. Treatment with all three BMPs was able to rescue the formation of mineralized nodules that was inhibited by ATRA to a level that was similar to the control. In this capacity, treatment

\section{Day 4}

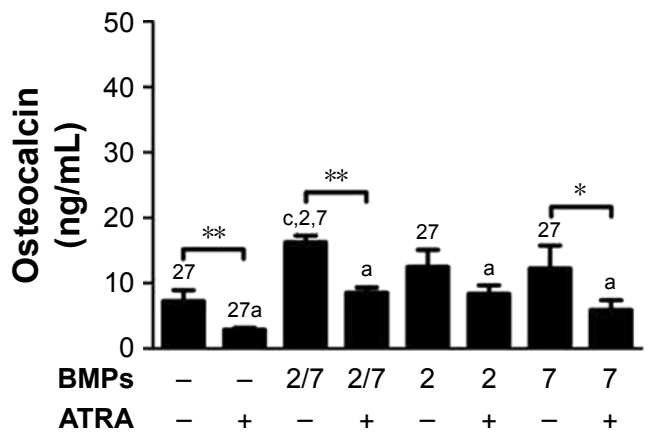

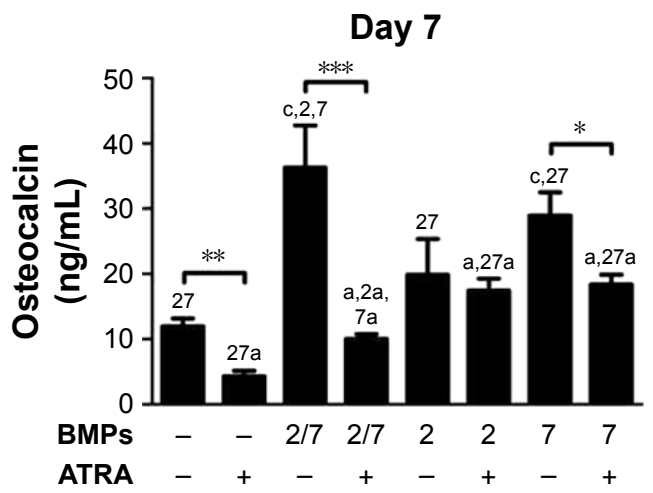

Figure 3 The expression of osteocalcin (OCN) of murine calvarial pre-osteoblasts (MC3T3-EI) under the different treatments.

Notes: I) no ATRA, no BMPs; 2) I $\mu$ M ATRA, no BMPs; 3) no ATRA, 50 ng/mL BMP2/7; 4) I $\mu$ M ATRA, 50 ng/mL BMP2/7; 5) no ATRA, 50 ng/mL BMP2; 6) I $\mu$ M ATRA, $50 \mathrm{ng} / \mathrm{mL}$ BMP2; 7) no ATRA, $50 \mathrm{ng} / \mathrm{mL}$ BMP7; 8) I $\mu$ M ATRA, $50 \mathrm{ng} / \mathrm{mL}$ BMP7 for 4 days and 7 days. All data are presented as mean values together with the standard deviation (SD). $* p<0.05, * * p<0.01$, *** $p<0.001$. 

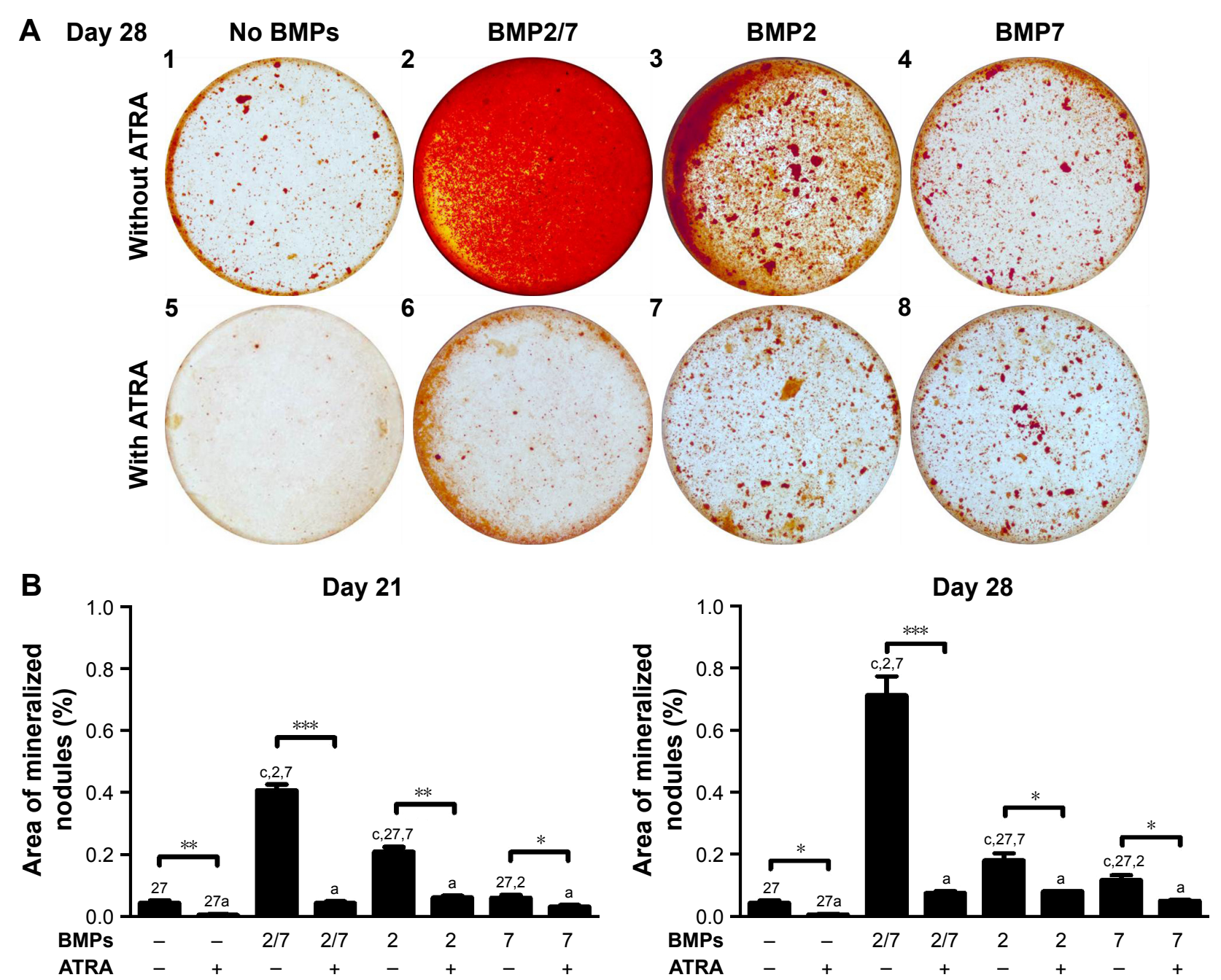

Figure 4 The mineralization of murine calvarial pre-osteoblasts (M3T3EI-EI) under the different treatment. (Above) Light micrographs depicting the mineralization (alizarin red staining) of murine calvarial pre-osteoblasts (MC3T3-EI cells) under the different treatments.

Notes: I) no ATRA, no BMPs (c); 2) I $\mu$ M ATRA, no BMPs (a); 3) no ATRA, 50 ng/mL BMP2/7 (27); 4) I $\mu$ M ATRA, 50 ng/mL BMP2/7 (27a); 5 ) no ATRA, 50 ng/mL BMP2 (2); 6) I $\mu$ M ATRA, $50 \mathrm{ng} / \mathrm{mL}$ BMP2 (2a); 7) no ATRA, $50 \mathrm{ng} / \mathrm{mL}$ BMP7 (7); 8) I $\mu$ M ATRA, $50 \mathrm{ng} / \mathrm{mL}$ BMP7 (7a) for 21 days and 28 days. (Below) Graph depicting the calcification area of murine calvarial pre-osteoblasts (MC3T3-EI cells) per well under the different treatments: I) no ATRA, no BMPs (c); 2) I $\mu$ M ATRA, no BMPs (a); 3) no ATRA, $50 \mathrm{ng} / \mathrm{mL}$ BMP2/7 (27); 4) I $\mu$ M ATRA, $50 \mathrm{ng} / \mathrm{mL}$ BMP2/7 (27a); 5) no ATRA, 50 ng/mL BMP2 (2); 6) I $\mu$ M ATRA, $50 \mathrm{ng} / \mathrm{mL}$ BMP2 (2a); 7 ) no ATRA, 50 ng/mL BMP7 (7); 8 ) I $\mu$ M ATRA, $50 \mathrm{ng} / \mathrm{mL}$ BMP7 (7a) for 2 I days and 28 days. All data are presented as mean values together with the standard deviation $(\mathrm{SD})$. ${ }^{*} p<0.05$, $* * p<0.0 \mathrm{I}$, $* * * p<0.00 \mathrm{I}$. Abbreviation: ns, not significant.

with BMP2/7 was not superior to treatment with BMP2 or BMP7.

\section{Expression of osteogenic differentiation marker genes}

On both day 4 and day 7 , treatment with BMP2/7 alone induced significantly higher expression of Collagen I $\alpha$ than the control or treatment with either homodimeric BMP (Figure 5). Treatment with ATRA was able to significantly suppress the expression both in the absence or presence of all BMPs. On day 7, ATRA suppressed expression of Collagen I $\alpha$ to a significantly lower than the control, even in the presence of any of the three BMPs. The gene expression patterns of ALP and OCN were consistent with their protein expression. Treatment with ATRA significantly affected the expression of OCN, but not ALP. On day 7, BMP2/7 did not show any advantage over BMP2 or BMP7 in enhancing OCN gene expression in the presence of ATRA.

\section{Expression of BMP signaling key genes}

Dlx5 gene expression was significantly enhanced by treatment with BMP2/7 on day 4 and day 7 , and was enhanced by treatment with BMP2 on day 4 (Figure 6). Treatment with ATRA significantly downregulated Dlx 5 gene expression in both the absence of BMPs and in the presence of BMP2/7. However, ATRA treatment did not significantly influence Dlx5 expression in the presence of BMP2 and BMP7. BMP2/7 without ATRA could significantly increase Runx2 
A-1

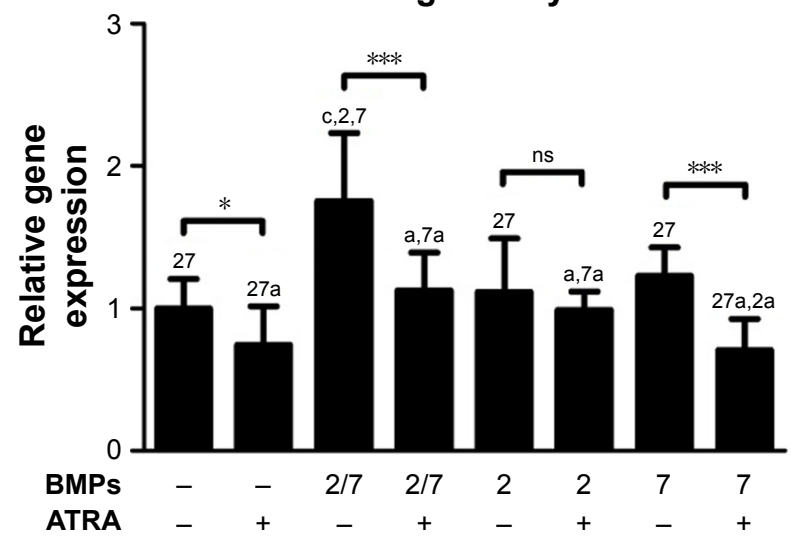

B-1

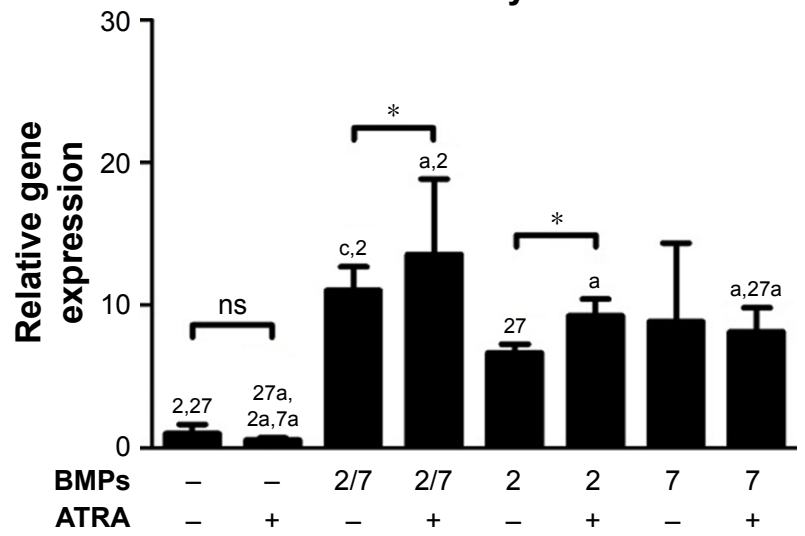

C-1

OCN day 4

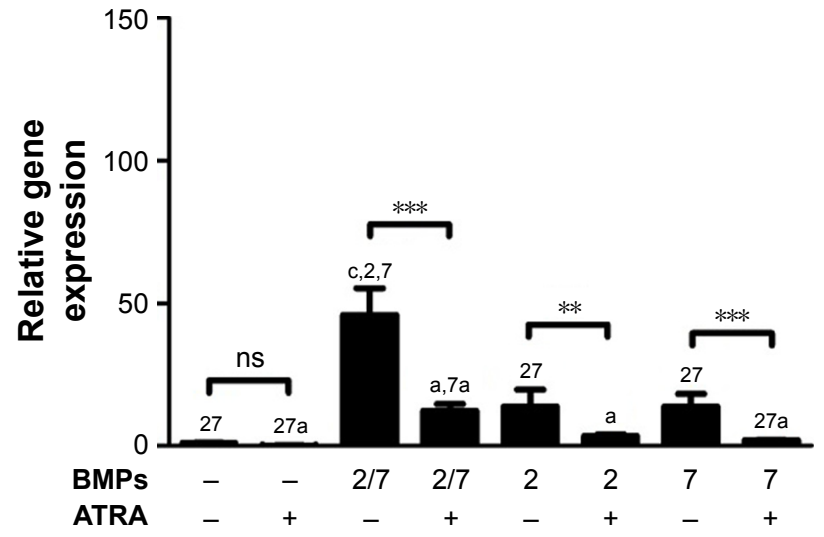

A-2

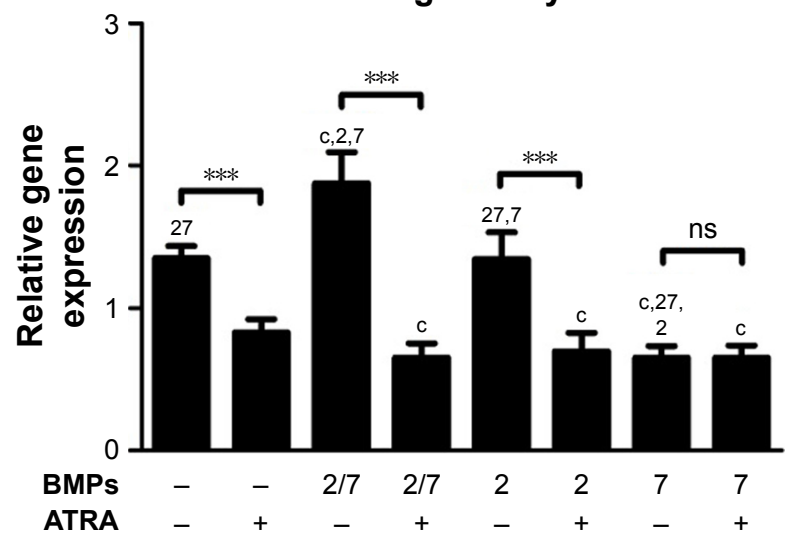

B-2

ALP day 7
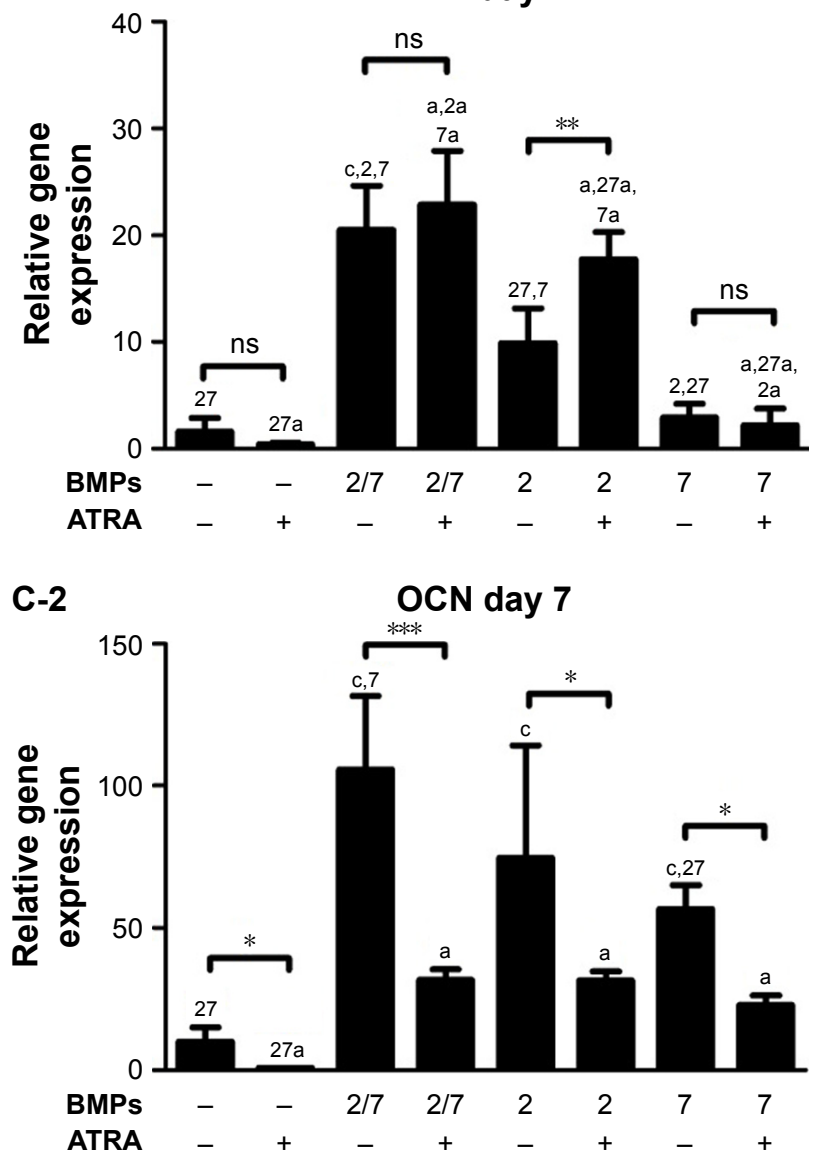

Figure 5 The relative gene expression of osteogenic differentiation marker genes under the different treatment.

Notes: Graph depicting the relative expression of (a) Collagen I, (b) Alkaline phosphatase and (c) Osteocalcin genes expression under the different treatments: under the different treatments: I) no ATRA, no BMPs (c); 2) I $\mu$ M ATRA, no BMPs (a); 3) no ATRA, 50 ng/mL BMP2/7 (27); 4) I $\mu$ M ATRA, 50 ng/mL BMP2/7 (27a); 5) no ATRA, $50 \mathrm{ng} / \mathrm{mL}$ BMP2 (2); 6) I $\mu$ M ATRA, $50 \mathrm{ng} / \mathrm{mL}$ BMP2 (2a); 7) no ATRA, 50 ng/mL BMP7 (7); 8) I $\mu$ M ATRA, 50 ng/mL BMP7 (7a) for 4 days and 7 days. The gene expression was first normalized to the corresponding $\beta$-actin gene expression for each sample. Then all the gene data were normalized to the gene data in control group on day 4 . All data are presented as mean values together with the standard deviation (SD). $*_{p}<0.05$, $*_{p} p<0.0$ I, $* * * p<0.001$.

Abbreviation: ns, not significant.

gene expression compared to control group. On day 4 and day 7, treatment with ATRA significantly affected Runx2 gene expression induced by BMP2/7, but not by BMP2 or BMP7. In the presence of ATRA, treatment with BMP2/7 did not induce higher expression of Runx2 than BMP2. Except for BMP7 on day 7, treatment with all BMPs induced a similar level of Runx2 gene expression, which was significantly higher than the ATRA group on day 4 and day 7 .

At both time points, treatment with BMP2/7 and BMP2 induced a significant increase in Osterix gene expression. 
Treatment with ATRA did not significantly affect Osterix gene expression in the presence or absence of either BMP homodimer, but ATRA treatment enhanced Osterix expression induced by BMP2/7 on day 7 .

On day 4, all the three BMPs induced significant increases in Smad1 gene expression. ATRA significantly reduced the increase of Smad1 gene expression due to BMP7 treatment.
On day 7, BMP2/7 and BMP2 induced a 5.8- and 3.3-fold increase in Smad1 gene expression compared to the control, respectively. ATRA significantly suppressed the Smad1 gene expression induced by BMP2/7 and BMP7, but not Smad1 gene expression induced by BMP2. In the presence of ATRA, all three BMPs induced a significant increase in Smad1 gene expression over treatment with ATRA alone.
A-1

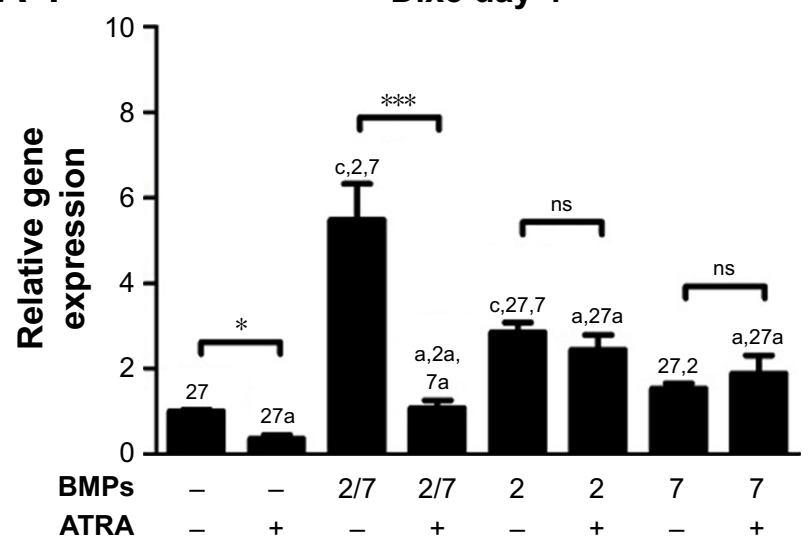

B-1

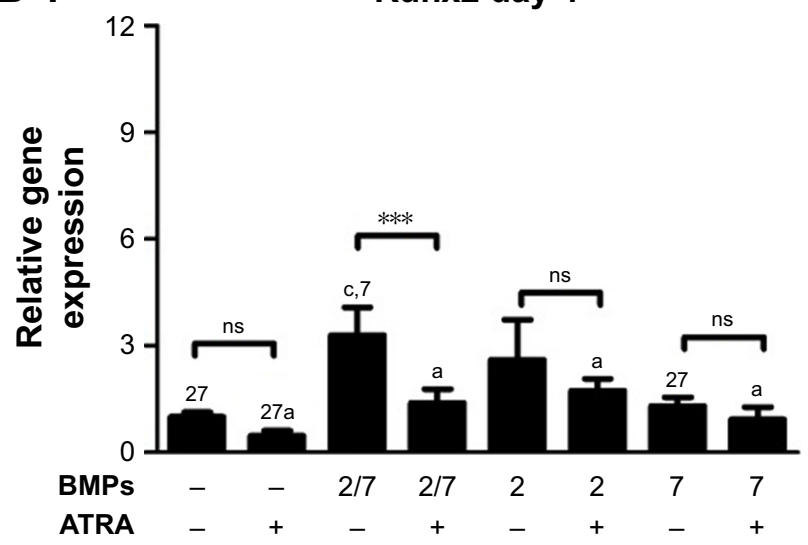

C-1

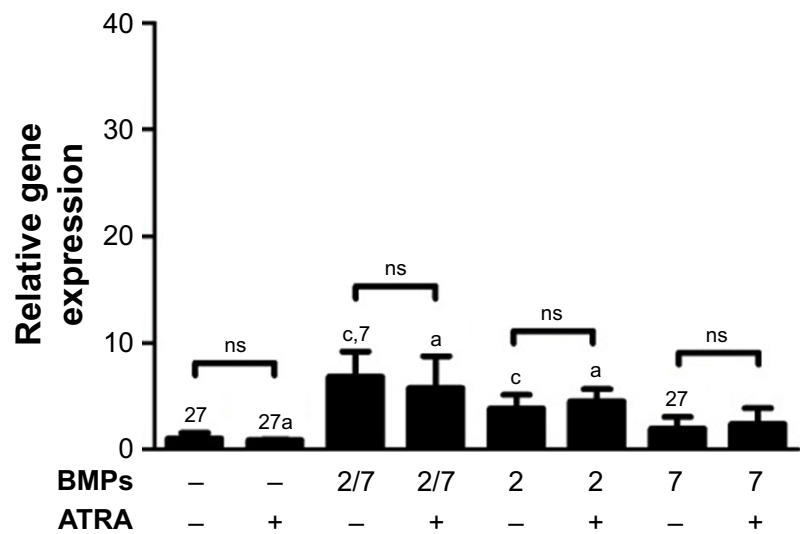

A-2

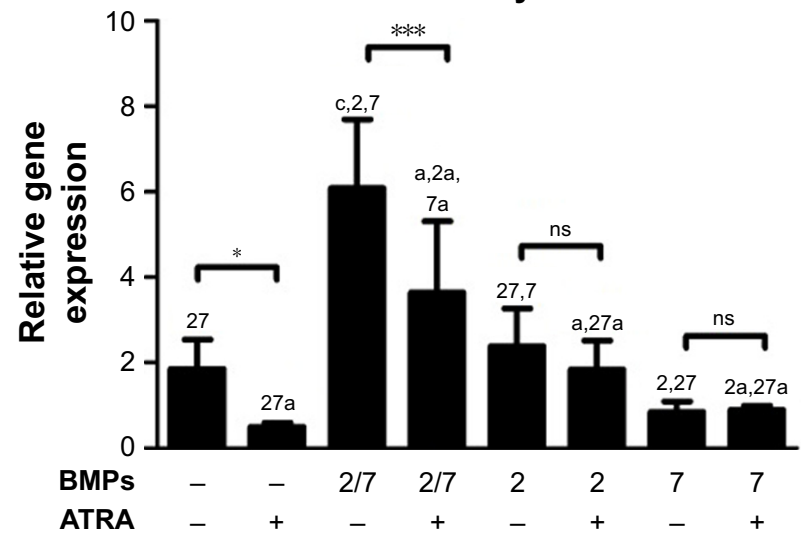

B-2

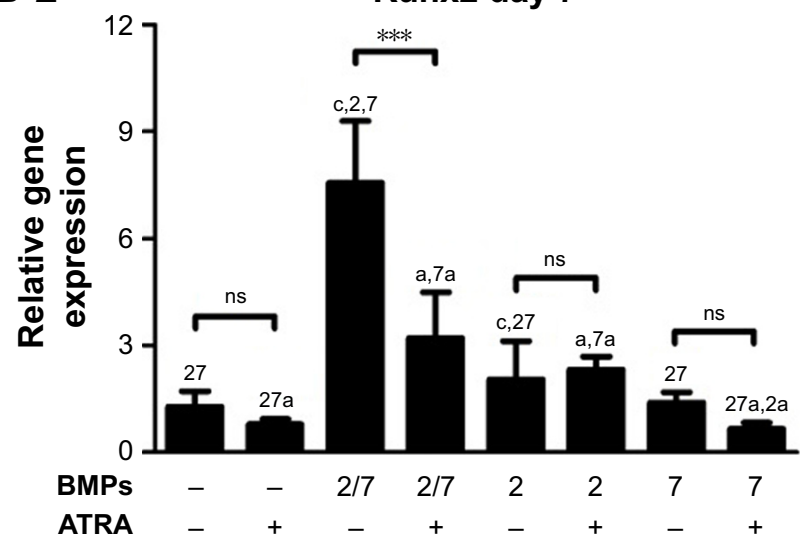

C-2

Osterix day 7

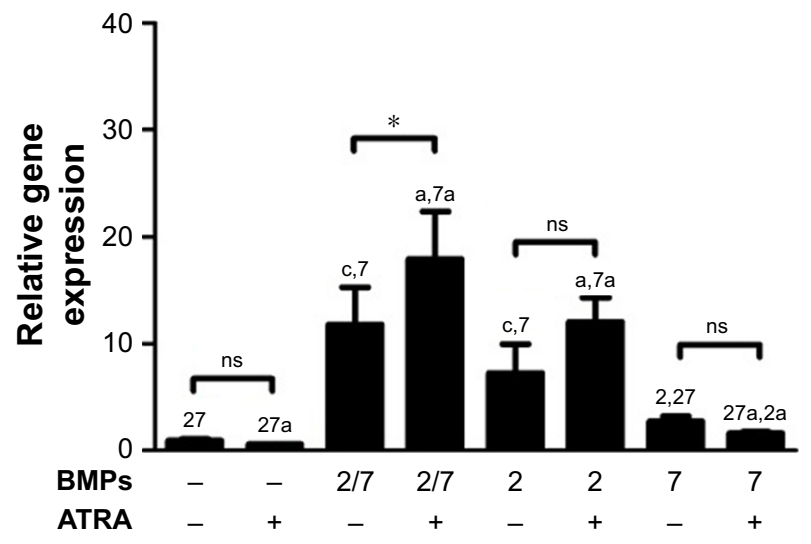

Figure 6 (Continued) 

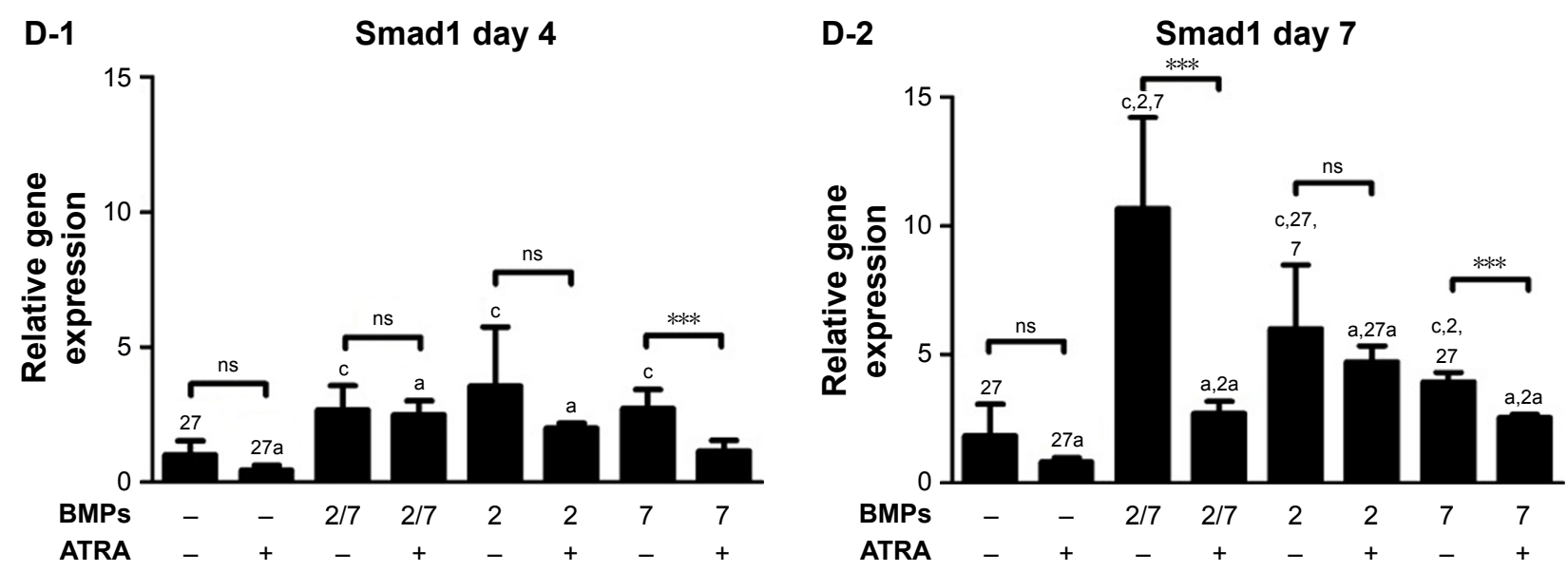

Figure 6 The relative gene expression of BMP signaling key genes under the different treatment.

Notes: Graph depicting the relative expression of (a) Dlx5, (b) Runx2, (c) Osterix and (d) Smad I genes expression under the different treatments: under the different treatments: I) no ATRA, no BMPs (c); 2) I $\mu$ M ATRA, no BMPs (a) ; 3) no ATRA, 50 ng/mL BMP2/7 (27) ; 4 ) I $\mu$ M ATRA, 50 ng/mL BMP2/7 (27a); 5 ) no ATRA, 50 ng/mL BMP2 (2); 6) I $\mu$ M ATRA, $50 \mathrm{ng} / \mathrm{mL}$ BMP2 (2a); 7) no ATRA, $50 \mathrm{ng} / \mathrm{mL}$ BMP7 (7); 8) I $\mu$ M ATRA, $50 \mathrm{ng} / \mathrm{mL}$ BMP7 (7a) for 4 days and 7 days. The gene expression was first normalized to the corresponding $\beta$-actin gene expression for each sample. Then all the gene data were normalized to the gene data in control group on day 4 . All data are presented as mean values together with the standard deviation (SD). ${ }^{*} p<0.05,{ }^{* *} p<0.0$ I, ${ }^{* * *} p<0.00$ I.

Abbreviation: ns, not significant.

\section{Discussion}

The restoration of large bone defects is very challenging, especially for patients with adverse systemic conditions, such as alcoholism. Animal studies demonstrate that chronic alcohol abuse can lead to substantial increases in ATRA concentration of various organ systems. ${ }^{15}$ High concentrations of ATRA are regarded as important mediators for alcoholism-related osteoporosis ${ }^{10}$ and compromised osteogenesis. ${ }^{11}$ In our previous studies, we demonstrated that heterodimeric BMP2/7 was able to antagonize the inhibitive effect of ATRA and rescue in vitro osteoblastogenesis of immortalized preosteoblast cells $\mathrm{s}^{31}$ and primary BMSCs. ${ }^{30}$ In this study, we, for the first time, compared the efficacy of heterodimeric BMP2/7 and homodimeric BMPs in antagonizing such effects of ATRA. In the presence of ATRA, BMP2/7 still induced significantly higher cell viability and early differentiation than the homodimers. However, ATRA significantly attenuated the advantages of BMP $2 / 7$ in inducing late and final osteoblastogenic differentiation over the homodimers.

ATRA-inhibited osteoblastogenesis was previously characterized as a partially differentiated non-proliferating state. ${ }^{39}$ These characteristics are based on the findings from our own research and other studies demonstrating that ATRA suppresses cell proliferation/viability, OCN expression and formation of mineralized nodules of osteoblasts, but does not influence or promote ALP activity of MC3T3-E1 preosteoblasts ${ }^{31,39}$ or primary mouse BMSCs. ${ }^{16,30}$ Our results demonstrated that the inhibitive effect of ATRA on cell viability did not occur immediately after treatment.
One potential mechanism is that ATRA binds to and inhibits adenine nucleotide translocase, thereby inducing mitochondrial permeability transition through obscure mechanisms. ${ }^{40}$ ATRA is shown to promote ALP activity in C3H10T1/2 $\mathrm{MSCs}^{41,42}$ and the rat preosteoblast cell line, UMR201-10B, ${ }^{43}$ whereas suppresses gene expression of Osterix and OCN in $\mathrm{C} 3 \mathrm{H} 10 \mathrm{~T} 1 / 2$ cells. ${ }^{42}$ On the other hand, ATRA is also shown to suppress adipogenic differentiation and to promote the osteogenic differentiation of adipose-derived stromal cells or of partially differentiated preadipocytes. ${ }^{44,45}$ These findings suggest a complicated role for ATRA in osteoblastogenesis. It is suggested that the different roles of ATRA are associated with its concentrations: ATRA at high concentrations promotes osteogenic differentiation, whereas ATRA at low concentrations can inhibit osteogenic differentiation. ${ }^{33}$ However, the dose-dependent mechanisms do not adequately explain the phenomena observed in the previous studies. It is important to note that a large number of the studies used ALP activity and gene expression as markers for osteogenic differentiation. However, ALP activity is only a marker of early osteogenic differentiation, and enhanced ALP activity does not necessarily lead to the late and final osteogenic differentiation. Furthermore, the promoting effect of ATRA on ALP gene expression is not through the classic osteogenic signaling pathways, such as promoting endogenous BMPs. Instead, this effect of ATRA is shown to be highly dependent on a retinoid acid response element in the promoter of the ALP gene. ${ }^{42}$ RA-induced osteogenic differentiation of ADAS seems to be dependent on RA-induced TGF- $\beta$ signaling, wherein it is demonstrated 
that RA enhances the endogenous expression of TGF- $\beta 1$ and TGF- $\beta 2 .{ }^{41}$ Furthermore, ATRA enhances the endogenous expression of $\mathrm{Smad} 3$, a key transcription factor involved in TGF- $\beta$ signaling, thereby initiating the displacement of a negative regulatory transcription factor CCAAT/EBP $\beta$, from the Runx 2 promoter. ${ }^{46}$ On the other hand, TGF- $\beta$ is also shown to inhibit BMP-2 induced osteoblastogenesis. ${ }^{20}$ All these molecular events may be accounted for the complicated and ambiguous effects of ATRA on osteoblastogenesis in different cell types.

During natural skeletal development, Runx2 is an upstream regulator of Osterix and D1x 5 expression. By contrast, during BMP-induced osteoblastogenesis, BMPtriggered p-Smad1/5 directly upregulates Dlx5, which is an upstream regulator that is independently able to regulate both Runx 2 and Osterix. ${ }^{47}$ In this study, we, for the first time, showed that heterodimeric BMP2/7 induced significantly higher expression of D1x5 than homodimeric BMP2 or BMP7. Consistently, BMP2/7 induced significantly higher Smad1/5 gene expression than the homodimeric BMPs at a later time point, suggesting a positive feedback regulation. The subsequent increase in Runx2 gene expression induced by BMP2/7 was significantly higher than that induced by BMP7 on day 4, and was also higher than Runx2 expression induced by both BMP2 and BMP7 on day 7. The BMP2/7induced expression of Osterix was higher than that induced by BMP2, and significantly higher than that induced by BMP7. These data indicated that BMP2/7 treatment induced higher activation of canonical signaling pathways and positive feedback signaling than BMP2 and BMP7 at the same concentration. Our data also showed that BMP2/7 triggered significantly higher activation of $\mathrm{p}$-Smad1/5 than BMP2 (data not shown), which indirectly supported the hypothesis that the higher potency of BMP2/7 might be attributed to a significantly higher binding affinity to both type I and type II receptors than the homodimers. ${ }^{48}$

In comparison with ATRA alone, all the three BMPs could significantly rescue the late differentiation marker, $\mathrm{OCN}$, and the final differentiation marker, mineralized nodules. Nevertheless, ATRA significantly suppressed OCN and mineralization, regardless of the potency of the different BMPs. Interestingly, the extent of the suppressive effect of ATRA did not correlate to the potency of BMPs. It seemed that ATRA was able to generalize the effect of BMPs, reduce the expression of OCN and impair the formation of mineralized nodules to a similar level as that of the control group. In contrast to BMP2 and BMP7, BMP9 is a special BMP that triggers both Smad1/5 and Smad2/3 to promote osteoblastogenesis. ${ }^{49}$
Zhang et al showed that ATRA can significantly potentiate BMP9-induced osteoblastogenesis. ${ }^{50}$ These contradictory findings underline the complicated and ambiguous modulation machinery of ATRA in osteoblastogenesis.

Hitherto, how BMPs and ATRA interact with each other in the process of osteoblastogenesis remains largely unknown. One study in embryonic stem cells suggested a potential mechanism for such an effect of ATRA: the signal duration of $\mathrm{p}-\mathrm{Smad} 1 / 5$ is significantly affected by ATRA by promoting Gadd45 and MAPK-mediated ubiquitination and proteasomal degradation of $\mathrm{p}-\mathrm{Smad} 1 / 5 .{ }^{35}$ However, our data did not demonstrate that the duration of $\mathrm{p}$-Smad1/5 activation was significantly compromised by ATRA in MC3T3-E1 preosteoblasts (data not shown).

In conclusion, although BMP2/7 was more potent in promoting osteoblastogenesis, BMP2/7 was not superior to homodimeric BMPs in antagonizing the inhibitive effects of ATRA on osteoblastogenesis. ATRA might affect BMP-induced osteoblastogenesis through a series of molecular mechanisms, including suppression of Dlx5 gene transcription. One of the limitations of this study was that we only used a murine-derived preosteoblast cell line. Although the MC3T3-E1 cell line has been frequently used to investigate the effects of BMP, ATRA and their combination on osteoblastic differentiation, current results should be validated in primary cells before being used to extrapolate in vivo mechanisms. Furthermore, a pertinent in vivo study is needed to show the interaction of ATRA and different BMPs in modulating in vivo bone regeneration.

\section{Acknowledgments}

This study was supported by the funds of National Natural Science Foundation of China (grant nos 81470724 and 81600844), Zhejiang Provincial Natural Science Foundation of China (grant no. LY14H140002 and LY17H140010), Science and Technology Department of Zhejiang Province (grant no 2017C33168), Guangdong Provincial Science and Technology Plan Project of China (grant no 2017A020211026) and Cultivation and innovation fund of Jinan University (grant no 21617312). This work of this paper was presented at the 43rd Annual European Calcified Tissue Society Congress, Rome, Italy, 14-17 May 2016, "All-trans retinoic acid can antagonize osteoblastogenesis induced by different BMPs irrespective of their dimerization types and dose-efficiencies" as a poster presentation with interim findings. The poster's abstract was published in "Poster Abstracts" in Journal Bone Abstracts (2016) 5 LB1: Hyperlink with DOI: 10.1530/boneabs.5.LB1. 


\section{Author contributions}

JW, HL and GW did experimental design; YL, XM, JG, ZL, $\mathrm{MZ}, \mathrm{JW}, \mathrm{JL}$ and GW performed the experiments and collected the data; YL, XM, JG, ZL, WB, JW, JL and GW did the data interpretation; YL, XM, JG, ZL, JL and GW wrote the manuscript. All authors contributed toward data analysis, drafting and revising the paper and agree to be accountable for all aspects of the work.

\section{Disclosure}

The authors report no conflicts of interest in this work.

\section{References}

1. Raggatt LJ, Partridge NC. Cellular and molecular mechanisms of bone remodeling. J Biol Chem. 2010;285(33):25103-25108.

2. Peacock A, Leung J, Larney S, et al. Global statistics on alcohol, tobacco and illicit drug use: 2017 status report. Addiction. 2018;113: 1905-1926.

3. Soares EV, Fávaro WJ, Cagnon VH, Bertran CA, Camilli JA. Effects of alcohol and nicotine on the mechanical resistance of bone and bone neoformation around hydroxyapatite implants. $J$ Bone Miner Metab. 2010;28(1):101-107.

4. Turner RT. Skeletal response to alcohol. Alcohol Clin Exp Res. 2000; 24(11):1693-1701.

5. Schnitzler CM, Mesquita JM, Shires R. Cortical and trabecular bone microarchitecture and turnover in alcohol-induced chronic pancreatitis: a histomorphometric study. J Bone Miner Metab. 2010;28(4): 456-467.

6. Backo H, Love J. Alcohol-induced osteopenia among in-custody and homicide deaths from the Harris County Institute of Forensic Sciences. J Forensic Sci. 2013;58(4):1055-1060.

7. Ulhøi MP, Meldgaard K, Steiniche T, Odgaard A, Vesterby A. Chronic Alcohol Abuse Leads to Low Bone Mass with No General Loss of Bone Structure or Bone Mechanical Strength $<$ sup/\&gt. J Forensic Sci. 2017;62(1):131-136.

8. Kanis JA, Johansson $\mathrm{H}$, Johnell $\mathrm{O}$, et al. Alcohol intake as a risk factor for fracture. Osteoporosis International. 2005;16(7):737-742.

9. Michael AR, Bengtson JD. Chronic alcoholism and bone remodeling processes: Caveats and considerations for the forensic anthropologist. J Forensic Leg Med. 2016;38:87-92.

10. González-Reimers E, Quintero-Platt G, Rodríguez-Rodríguez E, Martínez-Riera A, Alvisa-Negrín J, Santolaria-Fernández F. Bone changes in alcoholic liver disease. World J Hepatol. 2015;7(9): 1258-1264.

11. Camilli JA, da Cunha MR, Bertran CA, Kawachi EY. Subperiosteal hydroxyapatite implants in rats submitted to ethanol ingestion. Arch Oral Biol. 2004;49(9):747-753.

12. Lima CC, Silva TD, Santos L, et al. Effects of ethanol on the osteogenesis around porous hydroxyapatite implants. Braz J Biol. 2011;71(1): 115-119.

13. Trevisiol CH, Turner RT, Pfaff JE, et al. Impaired osteoinduction in a rat model for chronic alcohol abuse. Bone. 2007;41(2):175-180.

14. Carvalho IC, Martinelli CS, Milhan NV, et al. Prenatal alcohol exposure reduces mandibular calcium and phosphorus concentrations in newborn rats. J Oral Sci. 2016;58(3):439-444.

15. Kane MA, Folias AE, Wang C, Napoli JL. Ethanol elevates physiological all-trans-retinoic acid levels in select loci through altering retinoid metabolism in multiple loci: a potential mechanism of ethanol toxicity. Faseb J. 2010;24(3):823-832.

16. Wang A, Ding X, Sheng S, Yao Z. Retinoic acid inhibits osteogenic differentiation of rat bone marrow stromal cells. Biochem Biophys Res Commun. 2008;375(3):435-439.
17. Green AC, Martin TJ, Purton LE. The role of vitamin A and retinoic acid receptor signaling in post-natal maintenance of bone. $J$ Steroid Biochem Mol Biol. 2016;155(Pt A):135-146.

18. Bessa PC, Casal M, Reis RL. Bone morphogenetic proteins in tissue engineering: the road from laboratory to clinic, part II (BMP delivery). J Tissue Eng Regen Med. 2008;2(2-3):81-96.

19. Bessa PC, Casal M, Reis RL. Bone morphogenetic proteins in tissue engineering: the road from the laboratory to the clinic, part I (basic concepts). J Tissue Eng Regen Med. 2008;2(1):1-13.

20. Lee MH, Kim YJ, Kim HJ, et al. BMP-2-induced Runx2 expression is mediated by Dlx 5 , and TGF-beta 1 opposes the BMP-2-induced osteoblast differentiation by suppression of Dlx5 expression. $J$ Biol Chem. 2003;278(36):34387-34394.

21. Lee MH, Kim YJ, Yoon WJ, et al. Dlx5 specifically regulates Runx2 type II expression by binding to homeodomain-response elements in the Runx2 distal promoter. J Biol Chem. 2005;280(42):35579-35587.

22. Lee MH, Kwon TG, Park HS, Wozney JM, Ryoo HM. BMP-2-induced Osterix expression is mediated by Dlx 5 but is independent of Runx2. Biochem Biophys Res Commun. 2003;309(3):689-694.

23. Zheng Y, Wu G, Zhao J, Wang L, Sun P, Gu Z. rhBMP2/7 heterodimer: an osteoblastogenesis inducer of not higher potency but lower effective concentration compared with rhBMP2 and rhBMP7 homodimers. Tissue Eng Part A. 2010;16(3):879-887.

24. Lu H, Liu Y, Guo J, Wu H, Wang J, Wu G. Biomaterials with Antibacterial and Osteoinductive Properties to Repair Infected Bone Defects. Int J Mol Sci. 2016;17(3):334.

25. Boden SD, Kang J, Sandhu H, Heller JG. Use of recombinant human bone morphogenetic protein-2 to achieve posterolateral lumbar spine fusion in humans: a prospective, randomized clinical pilot trial: 2002 Volvo Award in clinical studies. Spine. 2002;27(23):2662-2673.

26. Govender S, Csimma C, Genant HK, et al. Recombinant human bone morphogenetic protein-2 for treatment of open tibial fractures: a prospective, controlled, randomized study of four hundred and fifty patients. J Bone Joint Surg Am. 2002;84-A(12):2123-2134.

27. Kaneko H, Arakawa T, Mano H, et al. Direct stimulation of osteoclastic bone resorption by bone morphogenetic protein (BMP)-2 and expression of BMP receptors in mature osteoclasts. Bone. 2000;27(4): $479-486$.

28. Uludag H, D'Augusta D, Palmer R, Timony G, Wozney J. Characterization of rhBMP-2 pharmacokinetics implanted with biomaterial carriers in the rat ectopic model. J Biomed Mater Res. 1999;46(2):193-202.

29. Wang J, Zheng Y, Zhao J, et al. Low-dose rhBMP2/7 heterodimer to reconstruct peri-implant bone defects: a micro-CT evaluation. $J$ Clin Periodontol. 2012;39(1):98-105.

30. Bi W, Gu Z, Zheng Y, Wang L, Guo J, Wu G. Antagonistic and synergistic effects of bone morphogenetic protein $2 / 7$ and all-trans retinoic acid on the osteogenic differentiation of rat bone marrow stromal cells. Dev Growth Differ. 2013;55(9):744-754.

31. Bi W, Gu Z, Zheng Y, Zhang X, Guo J, Wu G. Heterodimeric BMP-2/7 antagonizes the inhibition of all-trans retinoic acid and promotes the osteoblastogenesis. PLoS One. 2013;8(10):e78198.

32. Suzuki A, Ghayor C, Guicheux J, et al. Enhanced expression of the inorganic phosphate transporter Pit-1 is involved in BMP-2-induced matrix mineralization in osteoblast-like cells. J Bone Miner Res. 2006;21(5):674-683.

33. Henning P, Conaway HH, Lerner UH. Retinoid receptors in bone and their role in bone remodeling. Front Endocrinol. 2015;6:31.

34. Chen M, Huang HZ, Wang M, Wang AX. Retinoic acid inhibits osteogenic differentiation of mouse embryonic palate mesenchymal cells. Birth Defects Res A Clin Mol Teratol. 2010;88(11):965-970.

35. Sheng N, Xie Z, Wang C, et al. Retinoic acid regulates bone morphogenic protein signal duration by promoting the degradation of phosphorylated Smad1. Proc Natl Acad Sci S A. 2010;107(44):18886-18891.

36. Horii A, Wang X, Gelain F, Zhang S. Biological designer self-assembling peptide nanofiber scaffolds significantly enhance osteoblast proliferation, differentiation and 3-D migration. PLoS One. 2007; 2(2):e190 
37. Karakida T, Yui R, Suzuki T, Fukae M, Oida S. Retinoic acid receptor $\gamma$-dependent signaling cooperates with BMP2 to induce osteoblastic differentiation of C2C12 cells. Connect Tissue Res. 2011;52(5): 365-372.

38. Kuske B, Savkovic V, Zur Nieden NI. Improved media compositions for the differentiation of embryonic stem cells into osteoblasts and chondrocytes. Methods Mol Biol. 2011;690:195-215.

39. Kitching R, Qi S, Li V, Raouf A, Vary CP, Seth A. Coordinate gene expression patterns during osteoblast maturation and retinoic acid treatment of MC3T3-E1 cells. J Bone Miner Metab. 2002;20(5):269-280.

40. Notario B, Zamora M, Viñas O, Mampel T. All-trans-retinoic acid binds to and inhibits adenine nucleotide translocase and induces mitochondrial permeability transition. Mol Pharmacol. 2003;63(1):224-231.

41. Gazit D, Ebner R, Kahn AJ, Derynck R. Modulation of expression and cell surface binding of members of the transforming growth factorbeta superfamily during retinoic acid-induced osteoblastic differentiation of multipotential mesenchymal cells. Mol Endocrinol. 1993; 7(2):189-198

42. Hisada K, Hata K, Ichida F, et al. Retinoic acid regulates commitment of undifferentiated mesenchymal stem cells into osteoblasts and adipocytes. J Bone Miner Metab. 2013;31(1):53-63.

43. Choong PF, Martin TJ, Ng KW, Kw N. Effects of ascorbic acid, calcitriol, and retinoic acid on the differentiation of preosteoblasts. J Orthop Res. 1993;11(5):638-647.
44. Wan DC, Shi YY, Nacamuli RP, Quarto N, Lyons KM, Longaker MT. Osteogenic differentiation of mouse adipose-derived adult stromal cells requires retinoic acid and bone morphogenetic protein receptor type IB signaling. Proc Natl Acad Sci U S A. 2006;103(33):12335-12340.

45. Skillington J, Choy L, Derynck R. Bone morphogenetic protein and retinoic acid signaling cooperate to induce osteoblast differentiation of preadipocytes. J Cell Biol. 2002;159(1):135-146.

46. Dingwall M, Marchildon F, Gunanayagam A, Louis CS, WiperBergeron N. Retinoic acid-induced Smad3 expression is required for the induction of osteoblastogenesis of mesenchymal stem cells. Differentiation. 2011;82(2):57-65.

47. Ryoo HM, Lee MH, Kim YJ. Critical molecular switches involved in BMP-2-induced osteogenic differentiation of mesenchymal cells. Gene. 2006;366(1):51-57.

48. Guo J, Wu G. The signaling and functions of heterodimeric bone morphogenetic proteins. Cytokine Growth Factor Rev. 2012;23(1-2): 61-67.

49. Upton PD, Davies RJ, Trembath RC, Morrell NW. Bone morphogenetic protein (BMP) and activin type II receptors balance BMP9 signals mediated by activin receptor-like kinase- 1 in human pulmonary artery endothelial cells. J Biol Chem. 2009;284(23):15794-15804.

50. Zhang W, Deng ZL, Chen L, et al. Retinoic acids potentiate BMP9induced osteogenic differentiation of mesenchymal progenitor cells. PLoS One. 2010;5(7):e11917.
Drug Design, Development and Therapy

\section{Publish your work in this journal}

Drug Design, Development and Therapy is an international, peerreviewed open-access journal that spans the spectrum of drug design and development through to clinical applications. Clinical outcomes, patient safety, and programs for the development and effective, safe, and sustained use of medicines are the features of the journal, which

\section{Dovepress}

has also been accepted for indexing on PubMed Central. The manuscript management system is completely online and includes a very quick and fair peer-review system, which is all easy to use. Visit http://www.dovepress.com/testimonials.php to read real quotes from published authors. 